\title{
Formación de políticas públicas para la garantía de derechos humanos*
}

\author{
The making of public policies for the guarantee of human rights \\ Formação de políticas públicas para a garantia de direitos humanos
}

DOI: http://dx.doi.org/10.21803\%2Fpenamer.11.21.522

Pedro Alfonso Sánchez Cubides

https://orcid.org/0000-0002-9186-8010

Diego Mauricio Higuera Jiménez

https://orcid.org/0000-0002-0086-0065

\section{¿Cómo citar este artículo?}

Sánchez, P. \& Higuera, D. (2018). Formación de políticas públicas para la garantía de derechos humanos. Pensamiento Americano, 11(21 ), 26-44. DOI:http://dx.doi.org/10.21803\%2Fpenamer.11.21.522

\begin{abstract}
Resumen
El presente artículo aborda las políticas públicas como medio que tiene el Estado para respetar, proteger, garantizar y promover los derechos humanos, a través de planes programas, proyectos y actividades, en cuyo proceso de formación la participación de la sociedad es fundamental. Bajo la perspectiva del Estado Social de Derecho, cuyo presupuesto es la dignidad humana, la formación de políticas públicas con más relevancia debe orientarse a la materialización de derechos, proceso para el cual es de gran utilidad el enfoque basado en derechos, cuyos elementos se concretan en la delimitación del derecho, las obligaciones del Estado y los principios transversales.
\end{abstract}

PALABRAS CLAVES: Estado, políticas públicas, derechos humanos, enfoque basado en derechos.

\begin{abstract}
This article deals with public policies as a means for the State to respect, protect, guarantee and promote human rights, through plans, programs, projects and activities, in whose training process the participation of the society is fundamental. Under the perspective of the Social Rule of Law, whose budget (presupuesto) is human dignity, the formation of public policies with more relevance should be oriented to the embodiment of rights, a process for which the rights-based approach is quite useful, whose elements are specified in the delimitation of the law, the liabilities of the State and the cross-cutting principles.
\end{abstract}

KEYWORDS:: State, public policies, human rights, rights-based approach.

* Artículo de reflexión producto del proyecto de investigación "Las Políticas Públicas como Garantía de Derechos Humanos en Colombia", inscrito en la Dirección de Investigaciones de la Universidad Pedagógica y Tecnológica de Colombia -UPTC y vinculado al grupo de investigación Primo Levi de la Facultad de Derecho y Ciencias Sociales de la UPTC. 


\section{Resumo}

O presente artigo aborda as políticas públicas como meio que o Estado tem para respeitar, proteger, garantir e promover os direitos humanos, através dos planos programas, projetos e actividades, cujo proceso de formação da participação da sociedade é fundamental. Sob a perspectiva do Estado Social de Direito, cujo presuposto é a dignidade humana, a formação de políticas públicas com mais relevância deve orientar-se à materialização de direitos, processo para qual é de grande utilidade o enfoque baseado em direitos, cujos elementos se concretizam na delimitação do direito, nas obrigações do Estado e nos princípios transversais.

PALAVRAS CHAVE: Estado, políticas públicas, direitos humanos, enfoque baseado em direitos.

\section{Perfil}

Magister en Gestión de Proyectos Socio Productivos, PhD (c) en Proyectos.

Universidad Estatal de Bolívar. Guaranda - Ecuador.

pedro.sanchezO2@uptc.edu.co

\section{Perfil}

Magíster en derecho público y ciencia política, Université Nancy 2 Francia; abogado, Universidad Santo Tomás, Seccional Tunja; Co investigador del Grupo de Investigación Primo Levi de la Facultad de Derecho y Ciencias Sociales de la UPTC; Director del Semillero de Investigación Veritas Est Font Libertatis de la Universidad Santo Tomás, Seccional Tunja; Director del Doctorado en derecho público de Universidad Santo Tomás, Seccional Tunja. higuerajimenez.abogado@gmail.com

\section{Pedro Sánchez Cubides}

Posdoctor en educación, ciencias sociales e interculturalidad, Universidad Santo Tomás,

\section{Diego Higuera Jiménez}




\section{Introducción}

D esde que los seres humanos han requerido protección y, además, unos han obedecido a otros, se puede decir que existe el Estado. Sin embargo, en la perspectiva moderna, el Estado es la personificación jurídica de la Nación. Es la organización institucionalizada del poder político que posee monopolios como la coerción, el derecho, la creación de tributos y la soberanía, entre otros. A través del monopolio de la fuerza legítima hace cumplir las normas jurídicas que dicta. Es a través del Estado que los ciudadanos se organizan para desarrollar el proceso de emancipación a través de la materialización de la razón, la libertad, la igualdad, la justicia y la dignidad como valores de la modernidad.

El Estado como ser colectivo, superior a las personas que representa, actúa en su nombre mediante la distribución de poderes y recursos, al igual que regulando la vida en sociedad, todo en aras de generar condiciones de bienestar y mejorar la calidad de vida de sus integrantes. Por tal motivo, las acciones del Estado se orientan a realizar objetivos de interés público de manera eficiente y eficaz, entre los que se encuentran el respetar, proteger, garantizar y promover los derechos humanos, para lo cual cuenta con las políticas públicas.

En este sentido, formación de políticas públicas representan una gran importancia para la garantía de derechos humanos, razón que justifica su presentación y análisis, actividad para la cual metodológicamente se revisaron diferentes fuentes bibliográficas especializadas en la temática, al igual que algunas normas jurídicas. El artículo está organizado en tres partes: hacia una comprensión de las políticas públicas, hacia una comprensión de los derechos humanos y una aproximación al vínculo de políticas públicas y derechos humanos.

\section{Hacia una comprensión de las políticas públicas}

A continuación, se presenta y analiza el concepto de política pública, al igual que el ciclo de una política pública.

\subsection{Concepto de política pública}

Según Sánchez (2016) por política pública se entiende el conjunto de decisiones a corto, mediano y largo plazo, del Estado, diseñadas por las autoridades competentes investidas de poder y legitimidad, con el propósito de gestionar el conflicto social para lo cual se requiere movilizar recursos, utilizar estrategias y líneas de acción, formular e implementar planes, programas, proyectos $y$ actividades con el fin de cumplir objetivos y metas, en cuyo proceso de formación o fases debe existir participación de agentes diferentes a las autoridades públicas.

Como se puede apreciar en el anterior concepto, el gran propósito de las políticas públicas es gestionar el conflicto social, es decir, transformar una situación socialmente problemática en una situación deseable y posible para los miembros de un determinado grupo social, el cual no se alcanza con la expedición de normas jurídicas, a través de principios, reglas, valores y directrices, que si bien es cierto permiten formalizar la política pública, ésta no es una sola decisión o curso de acción, sino un conjunto de decisiones (Rubio, 2013). Además, según Aguilar (2012) dicho propósito requiere del manejo responsable de los recursos públicos, la participación de los ciudadanos, la transparencia, la rendición de cuentas a los ciudadanos y el interés general, de tal manera que el proceso de formación de políticas públicas exige que el uso de los recursos de diversa índole y las inversiones públicas produzcan los máximos beneficios sociales, económicos y ambientales, cuya gestión no debe permitir que personas, especialmen- 
te los servidores públicos, se aprovechen de tales recursos en beneficio particular quebrantando el interés público. Adicionalmente, el referido proceso coloca al ciudadano en el centro de atención, al incluir elementos de las prácticas del bueno gobierno, en donde la participación es factor importante al darle al ciudadano responsabilidades en el destino de la sociedad y de las actividades del Estado, lo que implica materializar la gobernanza en el sentido de generar espacios para que los actores diferentes a los estatales puedan jugar un papel protagónico en el proceso de formación de las políticas públicas, según sus necesidades reales, de tal manera que se realice el gobierno compartido.

En la democracia nacen y se sostienen las políticas públicas de tal manera que éstas deben ser el resultado de procesos deliberativos. Por lo tanto, es a través de la participación que los ciudadanos pueden definir los conflictos sociales y las alternativas de solución a través de consensos relativos que le imprimen legitimidad a dichas políticas. Tal participación se concreta a través de la democracia representativa y de la democracia participativa. El primer tipo de democracia funciona como representación política o de intereses en donde el ciudadano delega en una persona o conjunto de personas la competencia para que representen sus intereses ante las instancias de decisión política. En el segundo tipo de democracia, el ciudadano no delega en otros su participación en las deliberaciones públicas, pues actúa directamente, mediante mecanismos que coadyuvan en el vínculo del enfoque de los derechos humanos en las políticas públicas, tema que más adelante se desarrollará. En el caso de Colombia, de conformidad con el artículo 103 de la Constitución Política, tales mecanismos son: el plebiscito, el referendo, la consulta popular, el cabildo abierto, la iniciativa popular legislativa y normativa ante las corporaciones públicas, y la revocatoria del mandato. Otros mecanismos de participación directa son las audiencias públicas, la intervención de terceros y la consulta previa, entre otros.

De conformidad con la Ley 134 de 1994, el plebiscito es el pronunciamiento del pueblo convocado por el Presidente de la República, mediante el cual apoya o rechaza una determinada decisión del Ejecutivo, es decir, está relacionado con un hecho o suceso. El referendo es la convocatoria que se hace al pueblo para que apruebe o rechace un proyecto de norma jurídica o derogue o no una norma ya vigente, entendiendo por norma jurídica: acto legislativo, ley, ordenanza, acuerdo o resolución local. El referendo puede ser derogatorio o aprobatorio, al igual que puede ser nacional, regional, departamental, distrital, municipal o local. La consulta popular es la institución mediante la cual, una pregunta de carácter general sobre un asunto de trascendencia nacional, departamental, municipal, distrital o local, es sometida por el Presidente de la República, el gobernador o el alcalde, según el caso, a consideración del pueblo para que éste se pronuncie formalmente al respecto. La decisión del pueblo es obligatoria. El cabildo abierto es la reunión pública de los concejos distritales, municipales o de las juntas administradoras locales, en la cual los habitantes pueden participar directamente con el fin de discutir asuntos de interés para la comunidad. La iniciativa popular legislativa y normativa ante las corporaciones públicas es el derecho político de un grupo de ciudadanos de presentar proyecto de acto legislativo y de ley ante el Congreso de la República, de ordenanza ante las asambleas departamentales, de acuerdo ante los concejos municipales o distritales y de resolución ante las juntas administradoras locales, fundamentalmente. La revocatoria del mandato es un derecho político, por medio del cual los ciudadanos dan por terminado el mandato que le han conferido a un gobernador o a un alcalde. 
Las audiencias públicas, según la Ley 489 de 1998, artículo 33, son mecanismos de participación ciudadana que pueden ser solicitados por las entidades públicas estatales cuando lo consideren conveniente y oportuno, con el fin de discutir aspectos relacionados con la formulación, ejecución o evaluación de políticas y programas a su cargo. También las comunidades y las organizaciones pueden solicitar la realización de audiencias públicas, sin que la solicitud o las conclusiones de las audiencias tengan carácter vinculante para la administración, con la precisión que las razones de la decisión o decisiones que se tomen se deben explicar a dichas organizaciones. La intervención de terceros, de conformidad con la Ley 1437 de 2011, artículo 38 , se refiere a la posibilidad de que en los procesos administrativos los terceros puedan intervenir cuando resulten afectados con la actuación administrativa, adelantada en interés particular, o cuando la decisión que sobre ella recaiga pueda ocasionarles perjuicios. La consulta previa es un derecho que busca la inclusión y participación, desde la perspectiva étnica, de las comunidades que puedan verse afectadas al momento de tomar medidas legislativas o administrativas por parte del Estado.

Sin embargo, la democracia como fórmula ideal del sistema político que permite una adecuada relación entre el Estado y el ciudadano, con el transcurrir del tiempo, ha presentado un proceso de debilitamiento, caracterizado, según Gómez (2017), por los siguientes aspectos: una sociedad pluralista, en donde los protagonistas en los Estados democráticos no son los individuos sino los grupos; la reivindicación de intereses, en el sentido que la democracia moderna está asociada a una democracia representativa, la cual debe entenderse como una representación política y no de intereses; persistencia de las oligarquías, en referen- cia a que la derrota del poder oligárquico sigue siendo una deuda de la democracia contemporánea; el espacio limitado, debido a que la democracia no ha logrado copar todos los espacios de poder en donde se toman decisiones; el poder invisible, en relación a que las decisiones que tomen las autoridades públicas deben ser conocidas por todos los integrantes de una colectividad, existiendo eventos en que no es visible ese el referido proceso de toma de decisiones, mientras que el ciudadano es tenido en cuenta solamente para legitimar dicho proceso; y el ciudadano no educado, expresada tal situación por el desinterés del ciudadano por lo público, por el interés general, pues su preocupaciones se centran en el interés particular.

De otro lado, la política es pública, según Graglia (2016), porque el sujeto es el Estado como responsable principal y el objeto debe ser una sociedad como partícipe necesaria y primera destinataria. Es así como el Estado, a través de planes, programas, proyectos y actividades, decide y acciona a través del gobierno y la administración pública, respectivamente, junto con actores privados y públicos no estatales en la búsqueda del bien común que es la justificación de las políticas públicas, y la satisfacción social y la aprobación ciudadana como fines de tales políticas; contexto bajo el cual determinados planes, programas, proyectos y actividades no serían políticas públicas si el Estado no actúa como responsable principal, como es el caso de los gestionados por organizaciones no gubernamentales, o cuando el Estado decide y acciona a solas, es decir, sin generar espacios de participación de los ciudadanos o cuando los planes, programas, proyectos y actividades no están orientados al bien común, la satisfacción social y la aprobación ciudadana, por ejemplo las privatizaciones. Sin embargo, 
por el hecho de que el Estado sea el responsable principal de las políticas públicas no significa que la prestación de bienes y servicios públicos sea monopolio de éste, pues también pueden ser gestionados por terceros. Es así como en el contexto del Estado neo regulador, la implementación de las políticas públicas se lleva a cabo a través de los entes territoriales, los agentes privados y del sector público no estatal.

\subsection{El ciclo de la política pública}

El ciclo clásico de una política pública comprende la definición del problema, la inclusión en la agenda de gobierno, la formulación, la implementación y la evaluación. Las dos primeras etapas conforman la dimensión conceptual, la fase de formulación corresponde a la dimensión sustantiva y la fase de implementación es el momento operativo de la política pública, según Salazar (1999).

Sin embargo, según Graglia (2016), el diseño de una política pública debe partir del diagnóstico el cual permite identificar y jerarquizar las necesidadessociales según la urgencia y gravedad, enumerar y priorizar problemas según la frecuencia e incidencia, enumerar las alternativas y seleccionar las posibles, según la viabilidad financiera, humana política y de efectividad, proceso que debe ser participativo de actores políticos, sociales y temáticos. Antes de realizar el diagnóstico se deben analizar las políticas públicas existentes y determinar si hay planes, programas y proyectos faltantes o sobrantes con el fin de hacer las recomendaciones pertinentes y de esta manera alimentar el proceso de formación de tales políticas.

Surtido el diagnóstico, se debe llevar a cabo la toma de decisiones por parte de las autoridades públicas competentes, debido a que para abordar un problema pueden existir varias soluciones o alternativas posibles en término de fines, medios y contenidos. Debido al papel de diversos actores en el proceso de formación de la política pública, unos interesados, otros en contra; las decisiones no siempre son las más racionales o coherentes, pues el ideal es que sean el resultado de procesos de negociación. En la toma de decisiones se define la agenda de gobierno entendida como el listado de temas o problemas que reciben atención por parte de las autoridades públicas, aclarando que no todos los problemas que se incluyen en la agenda de gobierno son abordados y no todos los problemas abordados son resueltos.

Los gobernantes son los responsables de definir la agenda de gobierno. Dichos gobernantes son entendidos como las autoridades del poder ejecutivo elegidas por voto popular y los servidores públicos políticos que han sido designados por ellas. Un sentido más amplio, también debe incluir a los miembros de las corporaciones de elección popular. Una vez definida la agenda de gobierno, se deben formular, por parte de los planificadores, los planes, programas, proyectos y las actividades.

La formulación de la política pública permite seleccionar la alternativa más factible políticamente para lograr los efectos deseados, al igual que especificar y jerarquizar sus metas y objetivos, que deben estar en sintonía con la Constitución Política, las leyes y el plan nacional de desarrollo. Además, en dicha formulación se determinan los efectos esperados y los indicadores que permiten realizar el seguimiento o monitoreo en relación con cada objetivo y meta, para así verificar la efectividad de la política.

La implementación de la política pública permite pasar del discurso a la acción, es decir, a los hechos concretos. Sin embargo, es frecuente percibir la ejecución como un problema de la administración pública, netamente técnico. Esta fase implica Ilevar 
el tema que ocupa la política pública al terreno, a la realidad, situación que, por lo general, exige hacer reformulaciones parciales. Por ello, la implementación es más que un problema técnico, además porque su realización incide de una u otra forma en diversas personas.

No todas las políticas públicas utilizan el mismo diseño de implementación. Esta fase se puede soportar en motivaciones económicas, de sanciones o éticas, o combinar las tres motivaciones. Sabatier y Mazmanian (1979, citados por Roth, 2006, p. 81) señalan algunas condiciones para la implementación efectiva de las políticas públicas, a saber: el programa o programas ${ }^{1}$ que prevé la implementación debe estar fundamentado en una teoría sólida, la norma jurídica que formaliza la política pública debe contener, con claridad, las directrices de actuación, los objetivos jerarquizados, los recursos, las actividades técnicas y el proceso de implementación; los responsables de los entes encargados de la implementación deben disponer de capacidades políticas, de compromiso con los objetivos de la política pública y de gestión pública ${ }^{2}$; y la política pública debe disponer de apoyo activo durante todo el proceso de implementación por parte de los diferentes actores responsables e incidentes.

Sin embargo, con el transcurrir del tiempo la prioridad de los objetivos consignados en la norma jurídica que formaliza la política pública pueden perder importancia debido a la aparición de políticas públicas conflictivas o por cambios en las condiciones políticas o socioeconómicas, situaciones que obligan a su revisión. Estas circunstancias se pueden presentar porque una política pública con frecuencia no es un fracaso o éxito total.

La evaluación de la política pública permite retroalimentar su proceso de formación. Tal evaluación busca medir los efectos de las acciones públicas y los costos, mediante la recolección, verificación e interpretación de información sobre la ejecución y eficacia de la política pública. Esto significa que, además, de la evaluación de ejecución, se debe medir el impacto de la política mediante los indicadores de satisfacción y aceptación. En tal sentido, si el impacto logrado, según los destinatarios de la política, es mayor o igual al impacto deseado, según los gobernantes y planificadores, se debe continuar con la política pública. En cambio, si el resultado es menor, se debe controlar lo ejecutado para encontrar las fallas de inacción y corregirlas. La referida evaluación puede ser realizada por los ciudadanos, los políticos, los medios de comunicación y, en general, por organizaciones que pueden ser estatales o no estatales. La evaluación es una actividad normativa y comparativa que, además de permitir conocer los resultados de las acciones públicas, contribuye a mejorarlas, cuya realización se efectúa con anterioridad, durante y posterior a las referidas acciones públicas.

\section{Hacia una comprensión de los derechos humanos}

Los derechos humanos son facultades, categorías o reivindicaciones inherentes al ser humano que buscan su desarrollo integral, caracterizadas por la universalidad, inalienabilidad, imprescriptibilidad e inherencia. El Estado existe para garantizar, preservar y ex-

\footnotetext{
1. El plan nacional de desarrollo lo integran diferentes políticas públicas, a la vez que varios programas conforman una política pública. Un programa lo integran diversos proyectos.

2. Con sus aportes, la Nueva Gestión Pública contribuye a esta condición mediante la flexibilización organizacional y de procesos en búsqueda de mayor competitividad del sector público estatal, lo que implica procesos de descentralización, eficiencia en el uso de los recursos, participación ciudadana en los procesos de decisión y mayor satisfacción de los usuarios por los bienes y servicios ofertados por el Estado de manera directa o indirecta.
} 
tender a toda la población tales derechos

Los derechos humanos se abordan desde tres paradigmas, según Ortíz (2007): el escéptico, el derecho natural y el derecho positivo. El paradigma escéptico aborda los derechos humanos como ficciones, pues no se cree o se duda de tales derechos. El paradigma del derecho natural presenta los derechos humanos como eternos, naturales, inmutables, originados en Dios o la naturaleza humana, superiores a las normas positivas e independientes de las relaciones sociales, razones por las cuales los referidos derechos no requieren el reconocimiento de terceros. El derecho natural es una teoría ética y un enfoque filosófico del derecho que postula la existencia de derechos del hombre fundados en la naturaleza humana, son universales, anteriores, superiores e independientes al ordenamiento jurídico positivo y al derecho fundado en la costumbre, según Hervada (1998).

El paradigma del derecho positivo considera los derechos humanos como cambiantes, históricosy consignados en normasjurídicas provenientes del Estado o de organizaciones internacionales que pueden reclamarse en caso de inobservancia ante las autoridades judiciales del orden nacional o internacional. Sin embargo, es pertinente aclarar que las referidas normas jurídicas son el resultado de luchas políticas, ideológicas, sociales, epistémicas, económicas, jurídicas, ecológicas, morales, religiosas, científicas y étnicas de la humanidad desde la antigüedad hasta la actualidad.

En virtud del paradigma del derecho positivo, los derechos humanos consagrados en la actualidad en diversos textos de derecho internacional y en las constituciones de los Estados democráticos permiten que la comunidad política pueda ser justa y civilizada. Además, le imponen la obligación a los referidos Estados de respetar, proteger y materializar tales derechos, absteniéndose de interferir con su goce efectivo, previniendo su violación y adoptando medidas legislativas, administrativas, presupuestales y judiciales, entre otras.

\subsection{Tipologías de los derechos humanos}

Los derechos humanos se clasifican en derechos civiles y políticos o derechos humanos de primera generación, también conocidos como derechos de la libertad, clásicos o libertades fundamentales; derechos económicos, sociales y culturales o derechos humanos de segunda generación, también abordados como derechos de la igualdad, la subsistencia o del bienestar social; y derechos colectivos y del medio ambiente 0 derechos humanos de tercera generación, también referidos como derechos de la fraternidad. Además, con la globalización han surgido los derechos de cuarta generación que se ocupan del genoma humano, el ciberespacio, el internet, la libertad informática y las luchas por derechos de grupos minoritarios por lo poco visibles como los homosexuales, feministas, en condiciones de discapacidad, marginados o desplazados, entre otros. Finalmente, en la actualidad se está consolidando la quinta y sexta generación de derechos.

Según la Constitución Política de Colombia, los derechos civiles y políticos o derechos fundamentales se encuentran consignados en el Capítulo I del Título II, en donde, entre otros, se encuentran el derecho a la vida, integridad personal, libertad, igualdad, dignidad, personalidad, reunión, nacionalidad, nombre, sexualidad, matrimonio, unión libre, locomoción, intimidad, autonomía, petición, debido proceso, tutela o amparo, asilo, ocupación, habeas corpus y buena fe, entre otros.

Una perspectiva más amplia aborda los de- 
rechos fundamentales como sinónimo de derechos humanos. Sin embargo, aunque ambos son universales, absolutos e inalienables, la diferenciación existe, al establecer limitaciones a los derechos fundamentales, empezando por asociarlos a los de primera generación. Otra limitación, pero con unos mayores grados de libertad es aquella que los aborda como derechos superiores, establecidos internamente en una sociedad civil, por su Carta Política, en donde algunos derechos pueden ser restringidos, pero no vulnerados, son garantizados por las autoridades públicas y son llevados a nivel de positivización en normas jurídicas.

El limitar los derechos fundamentales a aquellos que se consagran en la Constitución Política bajo el título "de los derechos fundamentales" y excluir cualquier otro que ocupe un lugar distinto, no debe ser considerado como criterio determinante sino auxiliar, pues según Cepeda (1992) los derechos fundamentales no son exclusivamente los del Capítulo I del Título II. Los criterios puramente formales para identificar los derechos humanos fundamentales son una guía auxiliar pero no principal, determinante $\mathrm{y}$ suficiente. El concepto de derechos fundamentales es diferente del concepto de derechos de aplicación inmediata. Pueden existir derechos fundamentales no expresamente enunciados en la Constitución, puesto que aquellos que son inherentes a la persona humana son por su naturaleza fundamentales. No todos los derechos mencionados o definidos en la Constitución son fundamentales. Corresponde a los jueces señalar cuáles son los derechos fundamentales. Los tratados internacionales sobre derechos humanos ratificados por Colombia son una guía auxiliar en esta tarea doctrinaria, y el carácter fundamental de un derecho no hace relación a su mayor importancia frente a otros derechos considerados como no fun- damentales, sino a su naturaleza jurídica y lascircunstancia de tiempo, modo y lugar del caso. En síntesis, un derecho humano se considera como derecho fundamental si ha surtido la positivización jurídica y, además, se protege mediante la acción de tutela, es de aplicación inmediata y de prioridad hermenéutica, según Higuera (2015).

Los derechos económicos, sociales y culturales, consignados en la Constitución Política de Colombia en el Capítulo II del Título II, se integran por el derecho al trabajo, vivienda, familia, seguridad social, asociación, huelga, deporte, recreación, educación, propiedad privada e igualdad social, entre otros derechos. Los derechos colectivos y del ambiente, consignados en la Constitución Política de Colombia en el Capítulo III del Título II, se conforman por el derecho al ambiente natural y social, a la autodeterminación de los pueblos, a la imagen, a la creatividad, a la calidad de los productos, a las minorías, al patrimonio común de la humanidad y a la paz, entre otros derechos.

No obstante la anterior tipología, los derechos humanos son universales, es decir pertenecen a todos los seres humanos, en calidad de sujetos de tales derechos, en virtud del contrato social liberal que parte del principio de que todos los seres humanos somos iguales ante la ley; son indivisibles e interdependientes, pues para poder disfrutar de los derechos civiles y políticos, es necesario también de los derechos económicos, sociales y culturales, al igual que de los derechos colectivos y del ambiente, y viceversa. Ejemplos de lo anterior pueden ser: ¿De qué le sirve a una persona tener su derecho a la intimidad si no cuenta con una vivienda digna? ¿De qué le sirve a un ser humano la consagración del derecho a la vida, si no se cuenta con un buen servicio de salud o un ambiente sano? 


\subsection{Una mirada histórica de los derechos humanos}

Los derechos humanos no han surgido al mismo tiempo en el planeta, debido al desarrollo desigual de la humanidad en los diferentes ámbitos. La organización primitiva de los derechos humanos fue comunal, sin Estado, derecho y propiedad privada. En la edad antigua el modo de producción fue el esclavista que finalizó con la terminación del Imperio Romano de occidente en el siglo $\vee$ de nuestra era. Sin embargo, en América la esclavitud continuó hasta el siglo XIX.

En la edad media, ubicada cronológicamente del siglo $\vee$ al $X V$, el modo de producción fue la servidumbre. Los siervos no eran propiedad de los señores, pero no tenían la calidad de libres, pues debían obediencia absoluta al señor feudal. En la edad moderna se ha llevado a cabo la positivización de los derechos humanos en normas jurídicas, particularmente a partir de la segunda modernidad, es decir, del siglo XVIII, pues la primera modernidad comenzó en el siglo XV, como un conjunto de procesos sociales e históricos orientados a la civilización del mundo occidental, mediante los aportes del renacimiento, la investigación astrofísica, la reforma protestante, la expansión del capitalismo mercantil, los encuentros interculturales (Europa - América, Europa - Asia), la doctrina del antropocentrismo, y el surgimiento de la novela y el Estado nación. La segunda modernidad, caracterizada por la confianza en la ciencia y el progreso, permitió superar el paradigma de la razón divina, vigente en la época del Estado absolutista, que consideraba las acciones humanas como resultado de la voluntad y poder de Dios. A partir de esta modernidad se consolida un nuevo paradigma, el de la razón humana, soportado en la autonomía y la razón humana, que permite a los seres humanos comprender las leyes naturales de la sociedad y a partir de ellas ser libres y autogobernarse. La emancipación del ser humano se soporta en los valores de la modernidad: razón, libertad, igualdad, justicia y dignidad. Además, se consolidan los postulados del contrato social: legitimidad de los gobiernos, bienestar económico y social, seguridad e identidad colectiva, que aportan al discurso contractualista, que, además, justifica la existencia del Estado porque los ciudadanos le dan el poder regulador sobre la sociedad, requiriéndose este Ente para materializar los valores de la modernidad, es decir, se privilegia la razón de Estado, según Roth (2006).

La positividad jurídica de los derechos humanos ha permitido su mayor efectividad y validez debido a que su garantía se lleva a cabo por parte de los Estados, además de entes internacionales y organizaciones no gubernamentales, en el ámbito mundial. Sin embargo, es preciso aclarar que antes de la positividad jurídica, existían derechos humanos en las sociedades pre capitalistas, pues como se mencionó antes, tales derechos son el producto de luchas de diversa índole presentes en todos los tiempos históricos de la humanidad, además de las ideas filosóficas, políticas, morales, jurídicas, religiosas, raciales y ecológicas que han defendido la libertad, igualdad, solidaridad, equidad, dignidad, justicia, paz, pluralismo, tolerancia y el ambiente sano. En síntesis, los derechos humanos pertenecen al ámbito de las normas jurídicas, luchas e ideas de la humanidad.

En el contexto de las normas jurídicas, según Ortíz (2007), se distinguen cuatro estadios cronológicos: positivización, generalización, internacionalización y especificación. El punto de partida de la positivización de los derechos humanos en normas jurídicas son las declaraciones oficiales de derechos humanos: las norteamericanas de 1776 y las francesas de 1789 y 1793.

La Declaración de Derechos de Virginia del 12 
de junio de 1776 proclamó que todas las personas tienen derechos naturales que les son inherentes. La Declaración de Independencia Americana del 4 de julio de 1776, caracterizada por la proclamación de derechos y justificada, entre otros aspectos, porque la Corona Inglesa suprimió algunos derechos adquiridos por sus Colonias y por el incremento de impuestos para financiar las deudas que contrató Inglaterra durante la guerra de los siete años, 1756 - 1763. Sin embargo, los revolucionarios de 1776 no incluyeron en su proyecto la libertad para esclavos e indígenas.

La Declaración de los Derechos del Hombre y del Ciudadano de 1789 señaló que todas las personas disponen de derechos naturales e inalienables que los gobiernos no pueden ignorar: el derecho a la propiedad, libertad, seguridad, resistencia a la opresión, igualdad ante la ley, presunción de inocencia y libertad de opinión. Con la segunda Declaración de los Derechos del Hombre y del Ciudadano de 1793 se introdujeron algunos derechos sociales y culturales, como es el caso del derecho a la instrucción. Sin embargo, las mujeres y los niños no se incluyeron en las referidas declaraciones francesas, con las cuales se pone fin al Estado absolutista y surge el Estado nacional de derecho, perspectiva de Estado en la cual su organización humana se somete a un ordenamiento jurídico, la forma de gobierno es democrática, se reconocen derechos, hay división del poder público y el poder del Estado es limitado, representativo e institucionalizado.

Posteriormente a las declaraciones mencionadas, la generalización se ha materializado a través de las constituciones de los Estados nacionales desde el siglo XIX hasta el presente, primero consignando derechos de primera generación como resultado de las luchas populares y el pensamiento progresista, mientras que los derechos de segunda y tercera generación comenzaron su in- corporación en las referidas constituciones a partir de la segunda mitad del siglo XX.

El proceso de internacionalización de los derechos humanos que supera la órbita del Estado Nacional se presenta en el siglo XX a partir de la Declaración Universal de los Derechos Humanos llevada a cabo por la Asamblea General de las Naciones Unidas en 1948, momento desde el cual comenzó la consolidación de la perspectiva de Estado Social de Derecho o Estado de Justicia Social. Adicionalmente, dos textos fueron aprobados por la Organización de las Naciones Unidas - ONU en 1966: el Pacto Internacional de Derechos Civilesy Políticosy el Pacto Internacional de Derechos Económicos, Sociales y Culturales, cuya vigencia comenzó en 1976. La Declaración y los Pactos señalados anteriormente conforman el código internacional de derechos humanos y tienen el carácter de obligatorio para los Estados que forman parte de la ONU. Otros instrumentos internacionales son la Declaración Americana de los Derechos y Deberes del Hombre, el Convenio Europeo de Derechos Humanos y sus protocolos adicionales y el Pacto de San José de Costa Rica o Convención Americana sobre Derechos Humanos, entre otros.

El proceso de especificación, que implica la determinación de los sujetos titulares de derechos, se conforma por una serie de declaraciones de derechos humanos, entre las que se encuentran la Declaración de los Derechos del Niño, la Declaración sobe la Erradicación de la Discriminación de la Mujer y la Declaración de los Derechos del Disminuido Mental.

\subsection{Mecanismos de protección de los dere- chos humanos}

Existen mecanismos no institucionales, en el sentido que no poseen la fuerza del Estado y mecanismos institucionales que de manera articulada propenden por la protección de los derechos humanos. Dentro de 
los mecanismos no institucionales existen personas, naturales y jurídicas, nacionales e internacionales, que actúan en ese propósito, tales como gremios, organizaciones no gubernamentales, organizaciones políticas, académicos, artistas, entre otras personas.

En el ámbito de los mecanismos institucionales se encuentran entes administrativos, nacionales e internacionales, que desarrollan sus funciones y competencias en pro de gestionar, promover, proteger y socializar los derechos humanos. A nivel internacional están la ONU y la Organización de Estados Americanos - OEA, entre otros entes, mientras que, a nivel nacional, para el caso de Colombia, se encuentran los entes que tienen a cargo planes, programas, subprogramas, proyectos y actividades gubernamentales sobre el respeto, protección y materialización de derechos humanos, al igual que el Ministerio Público a través de la Procuraduría General de la Nación, la Defensoría del Pueblo y las personerías municipales y distritales.

También forman parte de los mecanismos institucionales los entes jurisdiccionales, internacionales y nacionales. Entre los entes jurisdiccionales internacionales se encuentra el Sistema Universal de Derechos Humanos, a través del Sistema Penal Internacional, en donde se resalta el papel de la Corte Penal Internacional, y los sistemas regionales de protección de los derechos humanos, entre los que se encuentra el africano, el europeo y el interamericano. Este último sistema regional forma parte de la OEA, cuyo papel protagónico se desarrolla a través de la Comisión Interamericana de Derechos Humanos y la Corte Interamericana de Derechos Humanos.
Para el caso de Colombia, los entes que forman parte de la jurisdicción constitucional conforman los entes jurisdiccionales nacionales, entre los que se encuentran la Corte Constitucional y los jueces que conocen acciones constitucionales tales como la acción de tutela, para la protección de derechos de primera generación; la acción de cumplimiento, para la protección de derechos de segunda generación, y las acciones popular y de grupo o clase, para la protección de derechos de tercera generación, entre otras acciones constitucionales. La jurisdicción constitucional ejerce el control de constitucionalidad que puede llevarse a cabo sobre conductas, para lo cual se sancionan las acciones $\mathrm{u}$ omisiones concretas de vulneración o amenaza de derechos de primera, segunda y tercera generación, mediante las acciones constitucionales antes señaladas. También el control de constitucionalidad se desarrolla sobre normas jurídicas $^{3}$, el cual puede ser a priori, es decir, antes de la promulgación de la norma o a posteriori, es decir, después de la promulgación de la norma.

\subsection{Los derechos económicos, sociales y culturales}

Los derechos económicos, sociales y culturales o de segunda generación buscan garantizar las condiciones mínimas de vida de todas las personas, propósito que se lleva cabo a través del proceso de formación de políticas públicas. La consolidación de los referidos derechos se ha soportados en los aportes de las religiones, especialmente del judaísmo, el islamismo y el cristianismo que propenden por la ayuda a los necesitados o pobres. En el caso del cristianismo se tiene como referente la economía de la salvación

3. Para el caso de Colombia, las normas jurídicas se integran en el bloque de constitucionalidad en sentido lato, conformado por el preámbulo, el articulado de la Constitución Política, algunos tratados y convenios internacionales de derechos humanos, de conformidad con el artículo 93 de la Carta Política, las leyes orgánicas y las leyes estatutarias, según la Sentencia C - 582 de 1999 proferida por la Corte Constitucional.

Pensamiento Americano Vol. 11 - No. 21 • Julio-Diciembre • Corporación Universitaria Americana • Barranquilla, Colombia • ISSN: 2027-2448 • http://coruniamericana.edu.co/publicaciones/ojs/index.php/pensamientoamericano 
del fin de la edad media que se caracterizó por la caridad, mediante la cual la ayuda permitía la salvación de los poderosos y la sujeción de los pobres y desvalidos, según Giraldo (2013).

También contribuyó a la consolidación de tales derechos la segunda Declaración francesa de los Derechos del Hombre y del Ciudadano de 1793 que incluyó el derecho a la instrucción que aportó a la beneficencia laica, la cual implicaba el control de las clases superiores sobre las inferiores a través de la caridad laica o legal; los aportes de filósofos y pensadores occidentales como Karl Marx, Inmanuel Kant y John Rawls; las contribuciones de programas políticos como la Sociedad Fabiana fundada en Londres en 1884 como un movimiento socialista británico que buscó avanzar en la materialización de los principios del socialismo mediante reformas graduales, las políticas bismarckianas en Alemania de finales del siglo XIX en materia de seguridad social, las Constituciones mexicana de 1917, soviética de 1918 y de Weimar de 1919 en Alemania, a través de la cual se introdujo el concepto de estado de bienestar; la creación de la Organización Internacional del Trabajo -OIT en 1919 y sus aportes en materia laboral básicamente a través de tratados internacionales, y la política intervencionista orientada a solucionar la crisis económica de los años treinta del siglo XX en Estados Unidos, conocida como New Deal (nuevo trato), nombre dado por el Presidente de ese entonces Franklin D. Roosevelt. Finalmente, aportaron a la referida consolidación la Declaración Universal de los Derechos Humanos, el Pacto Internacional de Derechos Económicos, Sociales y Culturales y las políticas beveredgianas que abordan los derechos sociales como una contraprestación que otorga la patria a las personas que estuvieron dispuestos a dar su vida por defenderla.

En cuanto a los derechos económicos, sociales y culturales, el Capítulo II del Título II de la Constitución Política de Colombia señala un catálogo extenso, desde el artículo 42 hasta el artículo 77. Sin embargo, para su garantía existen limitaciones, al consignarse en la Carta Política, artículo 86, que por regla general no es procedente la acción de tutela para hacerlos efectivos, debido a que los referidos derechos no tienen el carácter de fundamentales ${ }^{4}$, además de no ser definidos claramente y presentar ambigüedades. Adicionalmente, de conformidad con el Pacto Internacional de Derechos Económicos, Sociales y Culturales, artículo 2, las obligaciones de los Estados partes respecto de la implementación de tales derechos está limitada a la disponibilidad de recursos para adelantar los planes, políticas, programas y proyectos respectivos, razón por la cual los Estados cumplen las referidas obligaciones de forma progresiva en función de la gestión del conflicto social.

Por lo anterior, la defensa de los derechos económicos, sociales y culturales se efectúa a través de la acción de cumplimiento, bajo la limitante de recursos antes expresada, y de los mecanismos de tipo legal establecidos mediante planes, programas, políticas y proyectos para la materialización progresiva de tales derechos.

\section{Una aproximación al vínculo de políticas públicas y derechos humanos}

A partir de la Revolución Francesa tomó relevancia lo público, personificado en el Es-

4 . De manera excepcional se puede hacer uso de la acción de tutela para proteger o defender derechos económicos, sociales y culturales. Para proteger derechos que adquieren naturaleza de fundamentales por conexidad, es decir, porque su protección es necesaria para salvaguardar un derecho fundamental, y para tutelar derechos económicos, sociales y culturales que son fundamentales en sí mismos, es decir, aquellos de los cuales son titulares los niños, de conformidad con el artículo 44 de la Constitución Política. En la práctica, las excepciones se han convertido en regla general, debido a que muchas decisiones de la Corte Constitucional en materia de tutela se refieren a derechos de segunda generación.

Pensamiento Americano Vol. 11 - No. 21 · Julio-Diciembre • Corporación Universitaria Americana • Barranquilla, Colombia · ISSN: 2027-2448 • http://coruniamericana.edu.co/publicaciones/ojs/index.php/pensamientoamericano 
tado, supeditado a la voluntad del pueblo, cuyo gran propósito es respetar, proteger y materializar los derechos humanos, para lo cual cuenta con las herramientas específicas denominadas políticas públicas. Además, el Estado requiere ser administrado en función de las relaciones problema versus solución, y eficiencia y eficacia versus efectividad, desarrolladas por la administración pública, ciencia conocida como policía antes de la referida Revolución ${ }^{5}$, cuya tarea primordial es implementar las políticas públicas de tal manera que se pase del discurso a los hechos concretos.

En ese propósito, las políticas públicas deben ser el resultado del entrecruzamiento orgánico entre lo político y lo público, en el sentido que lo político es la forma en que se establece la sociedad, lo que implica que pertenezca al campo del poder político, mientras que lo público, según Sánchez (2015), está en función del interés general o de la utilidad común, concepto que en el marco de las actuales propuestas que orientan la administración pública, va más allá de lo estatal, pues incorpora también al sector público no estatal e inclusive en ocasiones al sector privado, situación que ha traído consigo que la frontera entre lo público y lo privado cada vez esté más desdibujada, pues hoy en día se aborda la gestión privada de lo público, caso en el que se encuentra la prestación de algunos servicios públicos como la educación, la salud, los servicios públicos domiciliarios, cuando son prestados por agentes privados. No obstante, lo anterior, el Estado como responsable principal de las políticas públicas, conserva ciertas facultades y mecanismos para asegurar y preservar el interés general, tales como la vigilancia, regulación y control a la prestación de tales servicios.

En la órbita de políticas públicas y derechos humanos, se tiene la perspectiva del Estado Social de Derecho, que hace alusión a un Estado cuyo presupuesto es la dignidad humana, motivo por el cual debe ser garante de los derechos humanos. En tal sentido, las políticas públicas se convierten en el medio para cumplir ese fin, razón por la cual dichas herramientas específicas deben incorporar en su núcleo los derechos humanos, para de esta forma hacer énfasis en lo social, en la construcción de lo público, lo político y la democracia.

En este propósito es de gran utilidad el enfoque de derechos humanos como una perspectiva para formar políticas públicas, mediante procesos participativos, en aras de materializar las garantías y libertades consignadas en las normas jurídicas a través de la provisión de bienes y servicios públicos, la regulación de actividades y la construcción de institucionalidad y democracia, en virtud de que en la democracia nacen y se sostienen las políticas públicas, como ya lo afirmamos, y éstas son el medio adecuado para la realización de derechos humanos, pues éstos son el objeto de tales políticas. Para ello se deben incorporar el desarrollo, según sus diferentes perspectivas, y la gobernabilidad en el proceso de formación de las referidas políticas públicas, que en el contexto del Estado neo regulador tiene como eje central la lucha contra la pobreza.

El enfoque de derechos humanos, entendido como medio para concretar dichos derechos, se caracteriza por los siguientes elementos, según Tejada (2004, citado por Jiménez 2013, p. 125): transversalidad en la concepción de los derechos humanos en los planes, programas, proyectos y actividades del Estado, principios

5. En referencia al aporte de Juan Enrique Von Justi, miembro del cameralismo, corriente alemana y austriaca del mercantilismo, a través del libro "Principios de ciencia de la policía". en donde planteó que el gran objeto de la policía era asegurar la felicidad de los ciudadanos mediante la sabiduría de sus reglamentos. Con la Revolución Francesa la policía pasó a ser conocida como administración pública, gracias al aporte de Carlos Juan Bonnin, autor progresista de la referida Revolución Francesa, precursor del derecho público y padre fundador de la ciencia de la administración pública, por medio del libro "Principios de la administración pública". 
de la no discriminación, dignidad humana y democracia; corresponsabilidad de todos los actores involucrados, predominio de la esfera pública y la resolución pacífica de conflictos; primacía de lo local en el ejercicio y realización de los derechos, para lo cual se debe fortalecer la descentralización territorial, expresada en transferencias de la nación de recursos, competencias y autonomías en lo político, lo administrativo y lo fiscal.

El enfoque de derechos humanos, basado en las normas internacionales sobre derechos humanos, se ha constituido en un marco conceptual para el proceso del desarrollo humano, el cual tiene al ser humano como razón de ser del desarrollo, que de conformidad con lo planteado por Cendales (2008), implica el acceso de las personas a las condiciones mínimas de bienestar, entre las que se encuentran: alimentación, vivienda digna, vestido, salud, recreación y educación. El desarrollo humano debe ser integral, es decir, además de las condiciones mínimas de bienestar señaladas, debe reunir los siguientes elementos: desarrollo cognoscitivo y cognitivo, desarrollo moral, desarrollo socio afectivo, desarrollo comunicativo, desarrollo laboral, liderazgo y desarrollo físico deportivo (Caro \& Vélez, 2013)

En aras de lograr la materialización del desarrollo humano cuyas consecuencias deben ser reducir la pobreza y, por supuesto, promocionar y proteger derechos; el Estado, en el caso de Colombia, destina del total del gasto público alrededor de la mitad al gasto público social, consignado en el artículo 350 de la Constitución Política, cuyo propósito es la provisión de bienes y servicios públicos tendientes a mejorar la calidad de vida y el bienestar de las personas, entre los que se encuentran: educación, salud, agua potable, saneamiento básico y vivienda. Es importante resaltar los servicios de educación y salud por generar externalidades positivas, pues el beneficio social es mayor al beneficio privado. En síntesis, el gasto público social debe orientarse a satisfacer necesidades básicas, a la corrección de desigualdades y a la formación de capital humano de tal manera que una sociedad avance en función del desarrollo en lo económico, social y ambiental.

Como se ha referenciado, el Estado tiene un papel protagónico en el proceso de formación de las políticas públicas como responsable principal para, por su conducto, garantizar los derechos humanos, en función del contrato social, la legitimidad y el poder político que acerca la sociedad a los objetivos de libertad, justicia, dignidad e igualdad, situación que le impone a todas las autoridades públicas el deber de la realización efectiva de tales derechos, con la participación de la sociedad, para lo cual los gobiernos deben tomar decisiones y la administración pública implementarlas en pro del bienestar colectivo. Sin embargo, en la práctica, el proceso de formación de las políticas públicas no permite garantizar algunos derechos humanos debido, entre otras, a las siguientes dificultades: falta de reflexiones multidisciplinarias orientadas a entender de manera más adecuada la realidad, ausencia de voluntad política, escasez de recursos, en donde el mismo Pacto Internacional de Derechos Económicos, Sociales y Culturales dejó la implementación de tales derechos a la disponibilidad de recursos. Otro factor que limita la realización de derechos es la corrupción que termina incidiendo en la formación de políticas públicas desarticuladas, no orientados al bien común, la satisfacción social y la aceptación ciudadana. También inciden los vacíos en los instrumentos internacionales y las normas constitucionales. En atención a tal situación la ONU, a través de sus organismos, según Alza (2014), ha realizado esfuerzos para delimitar el enfoque de derechos humanos al precisar lo siguiente:

Cuando se formulen las políticas y los programas de desarrollo, el objetivo principal 
deberá ser la realización de los derechos. Un enfoque basado en derechos humanos identifica a los ciudadanos y ciudadanas como titulares de éstos, el contenido de los derechos y los correspondientes titulares de deberes y obligaciones, procurando fortalecer las capacidades de los primeros para demandar su vigencia y de los segundos, para realizarlos o para crear condiciones para su vigencia. Los principios y las normas contenidos en los tratados internacionales de derechos humanos deben orientar toda la labor de cooperación y programación del desarrollo en todos los sectores y en todas las fases del proceso de programación (p.55).

Las precisiones de la ONU buscan que los derechos humanos no se queden en una simple proclamación jurídica y filosófica, pues si bien es cierto se han elevado a normas jurídicas y muchos de ellos son garantizados a través de la acción de tutela, convirtiéndolos en fundamentales, también es cierto que algunos derechos, especialmente de segunda generación, en algunos Estados aún no se garantizan a ciertas franjas de la población como se referenció. Es por ello que el enfoque de derechos humanos debe contribuir a que las decisiones que tomen los gobiernos sean efectivas, es decir, que su implementación sea viable, pues de lo contrario, seguirían vigentes las contradicciones entre la teoría y la práctica de los derechos humanos, pues una cosa es que los derechos existan en el ordenamiento político - jurídico formal y otra es que las personas logren gozar efectivamente de éstos o defenderlos en el momento que sean irrespetados. En ese sentido, según Alza (2014), el proceso de formación de políticas públicas bajo el enfoque de derechos debe observar los siguientes pasos: delimitar la política pública, delimitar el derecho, identificar las obligaciones estatales, verificar los principios transversales y establecer los contenidos específicos para verificar el enfoque de derechos en la política pública.

Delimitación de la política: como se puede observar, lo primero que se debe hacer en el proceso referido es identificar y delimitar en qué política pública se desea implementar el enfoque de derechos, además de establecer los elementos que aborda el análisis, para lo cual es necesario comprender el problema público que la política pública resolverá o evitará y la alternativa de solución seleccionada.

Delimitación del derecho: implica la identificación del derecho a partir de estándares nacionales e internacionales, y los elementos del contenido del derecho. En cuanto a la identificación del derecho, es importante resaltar que los derechos humanos son universales, indivisibles, interdependientes e interrelacionados, razón por la cual una política pública puede incidir en varios derechos. Como se ha referenciado, una política pública busca solucionar o evitar un problema público o varios problemas públicos, es decir, una problemática pública. Por tal razón, se debe comenzar con el derecho más directamente relacionado con el problema público principal a resolver, para luego elaborar progresivamente el análisis sobre los demás derechos con el ánimo de lograr la integralidad de los mismos.

En referencia a los elementos del contenido del derecho, es necesario establecer en qué consiste el principal derecho que la política quiere hacer vigente. Para ello se deben identificar los estándares de los derechos a partir de los instrumentos de derechos humanos en los que se encuentren reconocidos, tanto nacionales como internacionales, identificar el contenido mínimo de los derechos, a partir de un análisis normativo específico del sistema de derechos humanos, que incluye estándares nacionales e internacionales y jurisprudencia. 
Se ha vuelto costumbre abordar los siguientes cuatro elementos del contenido de los derechos: disponibilidad, accesibilidad, calidad y adaptabilidad. Disponibilidad significa que cuando el ciudadano lo necesite, el bien o servicio debe estar garantizado; accesibilidad hacer referencia a que cuando el ciudadano lo necesite, quiera recibir o gozar el bien o del servicio, debe lograrlo sin discriminación alguna. La accesibilidad puede ser física, económica, a la información y no discriminación. Calidad quiere decir que cuando el ciudadano recibe el bien o servicio debe ser óptimo para su goce y disfrute; y adaptabilidad en cuanto a que es necesario adecuar la política a la realidad social y cultural de las personas o comunidades en quienes influye.

Identificación de las obligaciones estatales: los planes, programas, proyectos y actividades del Estado, es decir, las políticas públicas, deben orientarse a respetar, proteger, garantizar y promover los derechos humanos. Respetar significa exigir al Estado que se abstenga de impedir, directa o indirectamente, el ejercicio del derecho. También respetar los derechos humanos es prestar los bienes y servicios públicos de calidad. Proteger se refiere a que el Estado está obligado a impedir que terceros menoscaben de algún modo el disfrute del derecho de las personas, escenario en donde el Estado intervienen a través de las regulaciones, vigilancia y control. Garantizar en alusión a que el Estado debe asegurar que el titular del derecho haga efectivo el derecho en los casos en que no puede hacerlo por sí mismo con los medios a su disposición. La realización del derecho se hace mediante la provisión, por parte del Estado, de bienes y servicios o a través agentes privados o públicos no estatales, pero bajo la vigilancia, regulación y control del Estado. Promover exige que el Estado adopte las medidas para que se difunda la información adecuada a cerca de las condiciones, formas, contenido y ejercicio del derecho y facilite que las personas ejerzan su derecho.

Verificación de los principios transversales: son postulados establecidos por la comunidad internacional que señalan los lineamientos que deben ser observados al momento de adoptar políticas de promoción y protección de derechos humanos. Los principios transversales son los siguientes: igualdad y no discriminación, progresividad y no regresividad, participación ciudadana en la toma de decisiones, transparencia y rendición de cuentas.

En cuanto al principio de igualdad y no discriminación es necesario identificar los grupos en condiciones de vulnerabilidad, identificar si la política pública toma en cuenta la realidad y los derechos de los pueblos indígenas, establecer el rol de las mujeres, de las personas con orientación social diversa, de las personas con discapacidad, de los niños, las niñas, los adultos mayores en las políticas públicas, y el impacto que los problemas y decisiones generan en ellos; precisar los mecanismos para garantizar la presencia de los anteriores grupos en las políticas públicas; establecer estrategias, actividades e instrumentos para atender la situación de los referidos grupos; evaluar los resultados y generar espacios de participación de los grupos señalados en el proceso de formación de la política pública. Con el fin de hacer visibles los grupos tradicionalmente discriminados, bajo el principio de igualdad y no discriminación, se pueden abordar los siguientes enfoques: pobreza, género, generacional, inclusivo o de discapacidad, intercultural y ambiental.

En referencia al principio de progresividad y no regresividad, se requiere identificar los derechos que se busca garantizar por parte el Estado, verificar que se hayan establecido medidas 
de respeto y garantía para los derechos que se buscan promover y proteger, al igual que asegurar los recursos para la implementación y que los planes, programas, proyectos y actividades alcancen sus fines, objetivos y metas.

El principio de participación ciudadana en la toma de decisiones implica que se establezcan los actores protagónicos, los espacios, momentos y mecanismos de participación. El principio de transparencia y rendición de cuentas hace alusión a que el proceso de formación de una política pública debe establecer responsabilidades sobre cada una de las obligaciones, mecanismos de acceso del ciudadano a la información sobre las decisiones estatales, y medios efectivos de queja y reclamos.

Establecer los contenidos específicos para verificar el enfoque de derechos en la política pública: significa que se deben analizar aspectos como la estructuración del problema público a resolver y las alternativas de solución, teniendo como razón de ser a la persona humana; la estructura organizacional y la suficiencia de recursos, las políticas y estrategias, y los planes, programas, proyectos y actividades.

\section{Conclusión}

El Estado tienen la responsabilidad de respetar, proteger, garantizar y promover los derechos humanos a todos los miembros de la colectividad, en atención al contrato social, la legitimidad, la efectividad y el poder político, con mucha más razón en el contexto del Estado Social de Derecho, cuyo presupuesto es la dignidad humana; para lo cual cuenta con las herramientas específicas denominadas políticas públicas, expresadas en planes, programas, proyectos y actividades, en cuyo proceso de formación es de gran utilidad el enfoque basado en derechos. Para alcanzar tales propósitos, los gobiernos deben tomar decisiones viables, de tal manera que la administración pública las pueda implemen- tar, para de esta forma pasar del discurso a la acción, proceso que requiere participación de la sociedad, con el fin de generar a toda población, mejor calidad de vida, para que los derechos humanos trasciendan las proclamaciones jurídicas y filosóficas y se conviertan en realidad. La materialización de derechos se alcanza mediante la provisión de bienes y servicios públicos, la regulación de actividades y la construcción de democracia e institucionalidad en búsqueda del bien común, la aceptación social y la aprobación ciudadana. Sin embargo, para efectos de la realización de derechos de segunda generación, que en determinadas circunstancias no pueden ser garantizados a toda la población, fundamentalmente debido a la escasez de recursos, el Estado se ve en la obligación de establecer procesos de focalización de tal manera que algunos bienes y servicios públicos orientados a hacer realidad un derecho de esa índole, prestado o financiado con recursos públicos, se oriente a las personas en situación de mayor pobreza. 


\section{Referencias}

Aguilar, L. (2012). Política pública: una visión panorámica. La Paz: Programa de las Naciones Unidas para el Desarrollo.

Alza, C. (2014). El enfoque basado en derechos ¿qué es y cómo se aplica a las políticas públicas? En derechos humanos y políticas públicas. Barcelona: Red de Derechos Humanos y Educación superior.

Caro, A., \& Vélez, L. (2013). Políticas públicas para la resocialización e integración social de los desmovilizados del conflicto armado interno en Colombia. Pensamiento Americano, 6 (11), 1327.

Cendales, L (2008). Planeación del desarrollo Territorial. Tunja: Grafiboy.

Cepeda, M. (1992). Los derechos fundamentales en la Constitución de 1991. Bogotá: Temis.

Colombia, Congreso de la República. (1994). Ley 134 de 1994. Bogotá.

(1998). Ley 489 de 1998. Bogotá.

(2011). Ley 7437 de 2011. Bogotá.

Asamblea Nacional Constituyente (1991). Constitución Política de Colombia. Bogotá.

Giraldo, C. (2013). Política social contemporánea en América Latina. Bogotá: Universidad Nacional de Colombia.

Gómez, J. (2017) Gerencia pública y control fiscal. Bogotá: Editorial Universidad del Rosario.

Graglia, J. (2016). Modelo relacional de políticas públicas. En políticas públicas, retos y desafíos para la gobernabilidad. Bogotá: Ediciones USTA.

Hervada, J. (1998). Cuatro lecciones de derecho natural. Pamplona: Ediciones Universidad de Navarra S.A.

Higuera, D. (2015). Protección de la dignidad humana: control de constitucionalidad e implementación de mecanismos internacionales. Bogotá: Grupo Editorial lbáñez.

Jiménez, W. (2013). Manual para el estudio y análisis de las políticas públicas y la gobernabilidad. Bogotá: Grupo Editorial Ibánez.

Ortíz, H. (2007). Derechos humanos. Bogotá. Grupo editorial Ibáñez.

Roth, A. (2006). Discurso sin compromiso. La política pública de derechos humanos en Colombia. Bogotá: Ediciones Aurora.
Rubio, E. (2013). Los valores constitutivos de los Derecho Humanos en Colombia: Una propuesta de formación para la vida. Pensamiento Americano, 6(11), 131-158.

Sánchez, P. (2015). El sector público estatal y las competencias de las entidades territoriales en Colombia. En derecho y realidad No. 25. Tunja: Universidad Pedagógica y Tecnológica de Colombia.

Sánchez, P. (2016). Las políticas públicas de educación superior en Colombia. Bogotá: Grupo Editorial Ibáñez.

Salazar, C. (1999). Las políticas públicas. Bogotá: Pontificia Universidad Javeriana.
2018, Vol. 11(21) 26-44 @The Author(s) 2018 Reprints and permission: www.americana.edu.co 